\title{
Estudo reológico da ação da bentonita como viscosificante de fluido de perfuração base água
}

\author{
SILVA,R.P ${ }^{1}$, MEDEIROS,A.L ${ }^{2}$ \\ Universidade Federal do Rio Grande do Norte, Departamento de Engenharia de \\ Petroleo \\ 2 Universidade Federal do Rio Grande do Norte, Departamento de Engenharia de \\ Materias
}

1

\begin{abstract}
RESUMO - Devido aos grandes desafios encontrados na perfuração de poços, há uma necessidade de se desenvolver fluidos com propriedades adequadas e capazes de atender todas as exigências da perfuração. As argilas bentonitas têm sua importância econômica por apresentar uma vasta gama de aplicações industriais. A bentonita pode ser usada como agente controlador de viscosidade de um fluido de perfuração, de modo a permitir uma maior eficiência no transporte de fragmentos de rochas para a superfície. Quanto às propriedades tixotrópicas, o uso da argila bentonita, permite que a suspensão assuma uma estrutura gelatinosa quando em repouso. Este trabalho objetivou observar o comportamento da bentonita como viscosificante e suas propriedades reológicas de filtração em fluidos de perfuração aquosos. Os resultados evidenciaram que as dispersões argila-água possuem um comportamento binghamianos e tixotrópico, apresentado potencial para utilização como agentes viscosificantes para fluidos de perfuração.
\end{abstract}

\section{INTRODUÇÃO}

Os fluidos de perfuração, também chamados de lamas, são indispensáveis à indústria de perfuração de poços de petróleo (Amorim et al., 2007). As principais funções dos fluidos durante as operações de perfuração são as seguintes: remover os detritos gerados pela broca, resfriar e limpar a broca e estabilizar as paredes do poço evitando seu desmoronamento.

Os fluidos de perfuração consistem em uma fase líquida contínua, tratada quimicamente de forma a adequar suas propriedades às operações de perfuração (Souza Santos, 1992; Amorim, 2003; Campos, 2007). Suas propriedades principais são densidade, viscosidade, homogeneidade, reatividade, filtrado e salinidade.

Em relação ao meio dispersante líquido, os fluidos podem ser de dois tipos: fluidos à base de água e fluidos não aquosos. Os fluidos a base de água são formados basicamente por água e argila do tipo bentonita, outras substâncias são adicionadas para que o fluido obtenha as propriedades desejadas. Estes aditivos podem ser: dispersantes, viscosificantes, agentes para controle de filtração, agentes de lubrificação e inúmeros outros compostos para funções específicas (Ferreira, 2005). 
Nos fluidos hidroargilosos são utilizadas argilas bentoníticas sódicas com a finalidade de aumentar a viscosidade do meio e formar o reboco, camada de baixa permeabilidade formada na parede do poço para impedir as perdas por filtração. É conhecido que, as bentonitas devem apresentar um alto grau de inchamento, característica presente preferencialmente nas bentonitas do tipo sódica (James et al., 2008).

Os fluidos à base de água e com argilas bentoníticas são os mais utilizados na maioria das perfurações em todo o mundo por serem considerados ecologicamente seguros, ao contrário, por exemplo, de fluidos à base de óleo. Esses últimos possuem alto poder de contaminação das formações geológicas com as quais entram em contato durante as perfurações. No Brasil, as argilas mais utilizadas no preparo de fluidos de perfuração são as argilas bentoníticas provenientes do município de Boa Vista, no estado da Paraíba.

Este trabalho objetivou observar o comportamento da bentonita como viscosificante e suas propriedades reológicas de filtração em fluidos de perfuração aquosos.

\section{Materias e Métodos}

$\mathrm{Na}$ Tabela I estão apresentadas as composições dos fluidos e a porcentagem de argila na sua composição.

Tabela I: Fluidos de perfuração preparados com argila

\begin{tabular}{|ccc|}
\hline Fluido & Agua $(\mathrm{ml})$ & Bentonita (\%) \\
\hline A & 500 & 2,5 \\
\hline B & 500 & 4,86 \\
\hline
\end{tabular}

A argila bentonítica utilizada foi do tipo sódica, industrializada da Paraíba, nas quantidades de 2,5 e $4,86 \%$ em massa de argila. O valor correspondente a $4,86 \%$ refere-se a ao especificado pela Petrobrás (Especificação N-2604 ) para fluidos de perfuração a base de agua doce.

\section{Metodologia}

No preparo dos fluidos de perfuração, a argila foi adicionada a $500 \mathrm{~mL}$ de água deionizada sob agitação a $17.000 \mathrm{rpm}$ durante $20 \mathrm{~min}$ em um agitador mecânico Hamilton Beach 936. A seguir o fluido permaneceu em repouso durante $24 \mathrm{~h}$ em recipiente fechado.

Passado o tempo de contato $24 \mathrm{~h}$, foi realizado o estudo reológico dos fluidos de perfuração. O fluido foi agitado durante 5 min no mesmo agitador mecânico a $17.000 \mathrm{rpm}$. Em seguida, foi transferido para o recipiente do viscosímetro Fann 35A. 


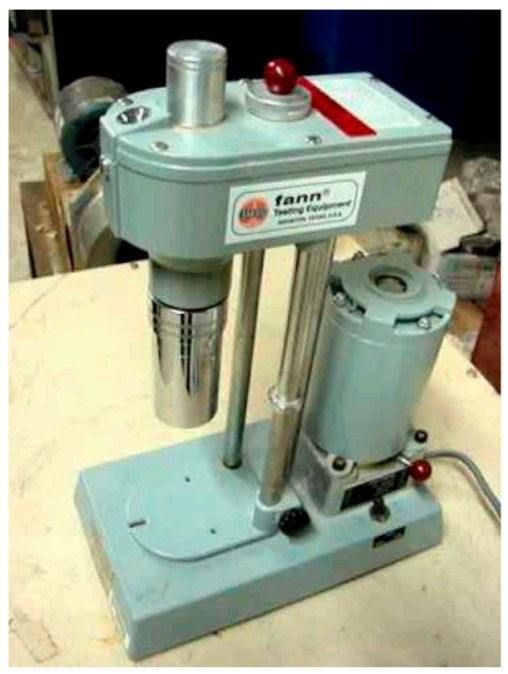

Figura 1: Viscosimetro Fann 35A

Após a agitação, o fluido foi transferido a um recipiente próprio para o armazenamento da amostra durante as medições. No viscosímetro Fann 35 A, foram lidos seis valores do ângulo de deflexão (torque) com taxas de cisalhamento variando de 5,1 a 1021,8 s-1. A leitura das medidas foi realizada da seguinte forma, baseando-se na Norma PETROBRÁS N-2605 (1998):

(i) Depois de 2 minutos a partir do ligamento do aparelho a velocidade de $600 \mathrm{rpm}$ foi lido o valor de $\theta 600$, isto é, a deflexão a $600 \mathrm{rpm}$;

(ii) Alterou-se a velocidade de rotação para 300 rpm e após 15 segundos foi lido o valor de $\theta 300$;

(iii) A velocidade foi então reduzida a $200 \mathrm{rpm}$ e esperou-se estabilizar para efetuar a leitura de $\theta_{200}$. O mesmo procedimento foi utilizado para as velocidades de $100 \mathrm{rpm}, 6 \mathrm{rpm}$ e $3 \mathrm{rpm}$ nas obtenções dos valores de $\theta_{100}, \theta_{6}$ e $\theta_{3}$.

A partir dos valores dos ângulos de deflexão lidos foi possível a determinação das viscosidades aparente (VA), plástica (VP) e limite de escoamento (LE), de acordo com a mesma norma:

(i) A viscosidade aparente, em cP, corresponde ao valor medido na leitura a $600 \mathrm{rpm}$ dividido por 2;

(ii) A viscosidade plástica, em cP, é a diferença das leituras obtidas a 600 e a 300 rpm;

(iii) $\mathrm{O}$ limite de escoamento, em N/m², é calculado como sendo a diferença entre a leitura a $300 \mathrm{rpm}$ e a viscosidade plástica.

Além das três grandezas, foi possível a determinação dos valores de forças géis conforme o seguinte procedimento:

(i) Manteve-se o fluido a velocidade de $600 \mathrm{rpm}$ durante 15 segundos;

(ii) Manteve-se em repouso por 10 segundos;

(iii) Alterou-se a velocidade para $3 \mathrm{rpm}$ e realizou a leitura registrando a maior deflexão do indicador como gel inicial $(\mathrm{G} 0)$ 
(iv) Manteve-se o fluido em repouso por 10 minutos;

(v) Alterou-se a velocidade para $3 \mathrm{rpm}$ e foi feita a leitura registrando a maior deflexão do indicador como força gel final $(\mathrm{G} f)$

Para a determinação do volume de filtrado, os fluidos foram agitados durante $1 \mathrm{~min}$, no agitador mecânico a $17.000 \mathrm{rpm}$. Em seguida, o fluido foi transferido para o recipiente do filtroprensa API, com aplicação de 7,0 kgf/cm2. Após $30 \mathrm{~min}$, o filtrado foi lido e obteve-se a medida do volume do filtrado, expresso em $\mathrm{mL}$.

\section{Resultados e Discursões}

A Fig. 2 e a figura 3 apresentam as curvas de tensão versus taxa de cisalhamento dos fluidos hidroargilosos (A e B, respectivamente). Os fluidos A e B apresentaram comportamento de fluidos binghamianos, independente da concentração de argila estudada. Nesse caso, os fluidos que se comportam como sólido até que uma tensão mínima, chamada de tensão de escoamento, seja excedida; em seguida, a relação entre a tensão e a taxa de cisalhamento torna-se linear.

\section{FLuido A}

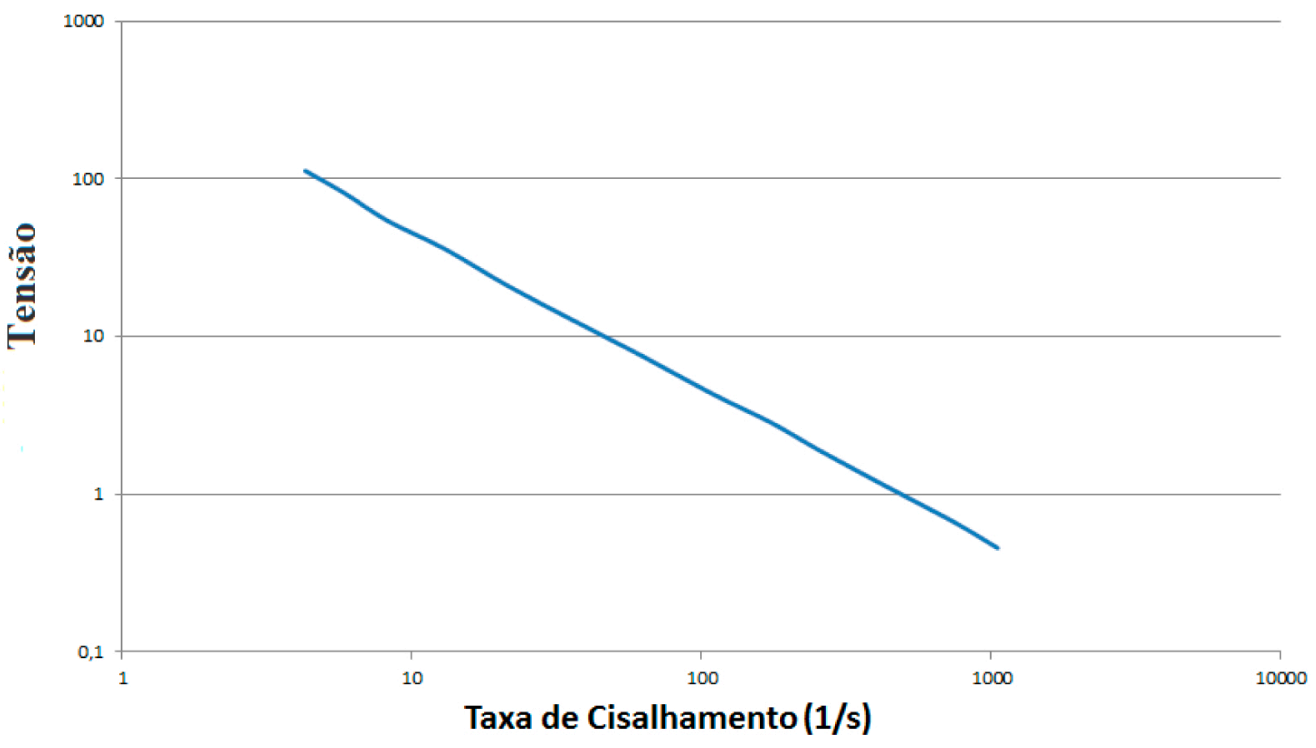

Figura 2 : Curva de tensão versus taxa de cisalhamento para o fluido A (2,5\% de argila) 
Fluido B

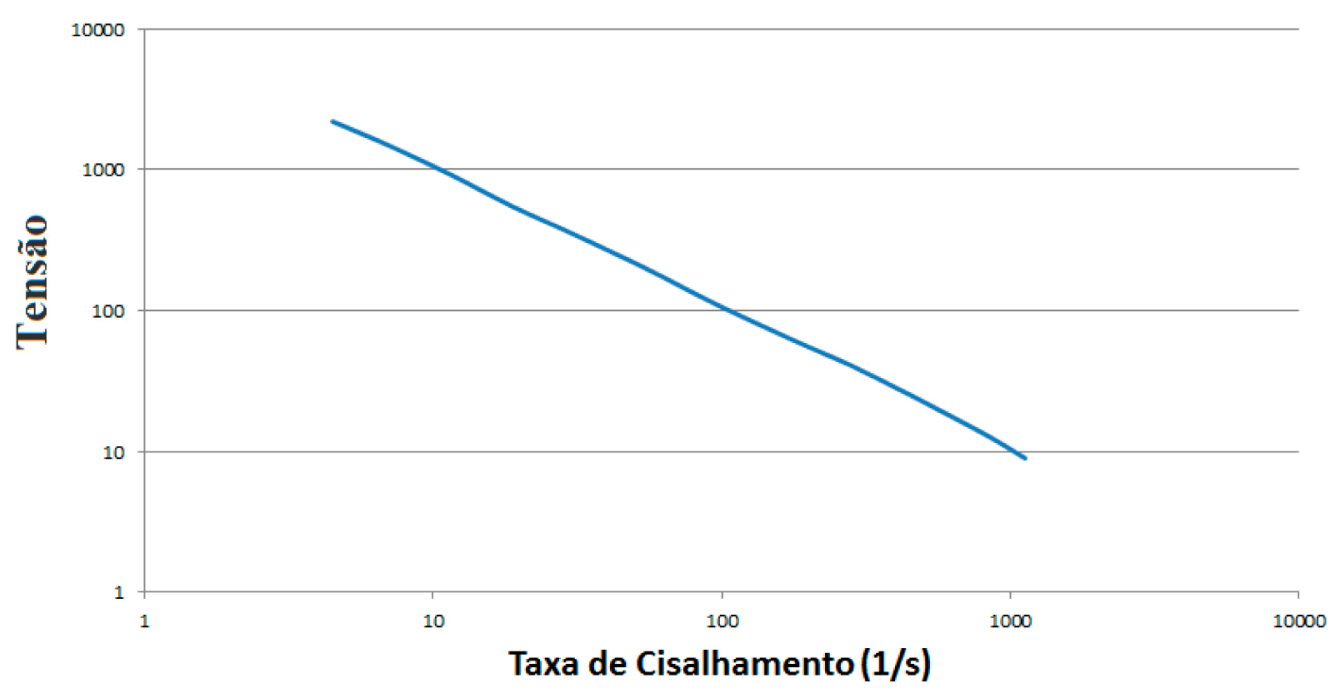

Figura 3 : Curva de tensão versus taxa de cisalhamento para o fluido B (4,86 \% de argila)

A tabela II apresenta as propriedades reologicas e de filtraçao do fluido.

Tabela II: Propriedades reologicas e de filtraçao dos fluidos estudados

\begin{tabular}{cccccc}
\hline Fluido & VA (cP) & VP (cP) & LE $\left(\mathrm{N} / \mathrm{m}^{2}\right)$ & FG $\left(\mathrm{N} / \mathrm{m}^{2}\right)$ & VF $(\mathrm{ml})$ \\
\hline A & 4,4 & 2,9 & 3,0 & 2,85 & 25 \\
B & 18 & 3,75 & 30 & 5,5 & 15 \\
Valor ideal & $\geq 15$ & $\geq 4$ & $\geq 1,5 \mathrm{VP}$ & ---- & $\leq 18$ \\
\hline
\end{tabular}

Observamos um aumento nos valores de VA, VP, LE e FG quando aumentamos a concentração da argila no fluido de perfuração. Segundo Amorin, 2005, esse aumento nos valores de VA decorre do aumento na intensidade das interações eletrostáticas e de massa entre as partículas sólidas, que se tornam predominantes com o aumento da concentração de argila.

Apesar das baixas concentrações de argila, foi possível observar que os fluidos apresentaram ainda a formação de gel. A força gel inicial mede a resistência inicial para colocar o fluido em fluxo. Já a final, neste mede a resistência do fluido para reiniciar o fluxo quando este fica certo tempo em repouso devido a manobras e conexões, por exemplo.

Valores muito baixos de forca gel não são desejados, pois a função do fluido de perfuração fica comprometida, uma vez que os cascalhos não permanecem em suspensão, decantando no fundo do poço e comprometendo o avanço da perfuração. Valores muito altos também não são desejáveis, pois ao retornar o fluxo, será exigida maior potencia das bombas do sistema de circulação. Embora não exista uma valor ideal fixo literatura para esse parâmetro, o fluido B apresentou um valor mais elevado de força gel, condicionado sua aplicação em fluido de perfuração. 
Os valores de volume de filtrado (VF) diminuíram à medida que aumentamos a concentração de argila. Como mencionado anteriormente, a maior concentração de argila no meio proporciona uma maior intensidade eletrostática e de massa entre as partículas, promovem a formação de reticulados que retêm as moléculas de água diminuindo, quantidade de água livre no sistema.

\section{Conclusões}

O experimentou permitiu observar e confirmar o bom desempenho da argila sódica como viscosificante e sua alta capacidade de inchamento quando aplicada em fluido de perfuração base água, o que condiciona sua aplicabilidade.

Observou-se que o fluido preparado com $4,86 \%$ de argila apresentaram valores mais próximos dos desejáveis, qualificando o mesmo para aplicação em fluidos à base de água doce.

$\checkmark \quad$ A argila sódica apresenta-se como um aditivo eficiente e ambientalmente correto quando aplicado em fluido de perfuração base água.

\section{REFERÊNCIAS}

Amorim, L. V.; Farias, K. V.; Silva, A. R. O.; Pereira, M. S.; Lira, H. L.; Ferreira, H. C. 2007. Desenvolvimento de formulações de fluidos base água para perfurações de poços de petróleo estudo preliminar. $4^{\circ}$ PDPETRO, Campinas, SP.

Campos, L. F. A., Composições de argilas bentoníticas para utilização em fluidos de perfuração de poços de petróleo, Tese de Doutorado apresentada ao Curso de Engenharia de Processos/CCT/UFCG, 2007.

FERREIRA, H. S., Obtenção de argilas organofilicas purificadas para uso em fluidos de perfuração base óleo, Dissertação de Mestrado Apresentada ao Programa de Pós Graduação em Ciência e Engenharia de Materiais, Novembro, 2005.

JAMES, O. O., M. ADEDIRAN MESUBI, F. A. ADEKOLA, E. O. ODEBUNMI, J. I. D. ADEKEYE. Beneficiation and characterization of a bentonite from north-eastern Nigeria. Journal of the North Carolina Academy of Science. 124 (4). 2008. pp. 154-158.

L. V. Amorim, C. M. Gomes, F. L. H. Silva, H. L. Lira, H. C. Ferreira, Águas Subterrâneas 19, 1 (2005) 75 .

L. V. Amorim, Melhoria, proteção e recuperação da reologia de fluidos hidroargilosos para uso na perfuração de poços de petróleo, Tese Dr., CCT, UFCG, Campina Grande, PB (2003).

Petrobrás - Argila aditivada para fluido de perfuração à base de água na exploração e produção de petróleo, Método, N -2605 (1998).

Souza Santos, P., Tecnologia de argilas, Ed. Edgard Blücher, Vol 3, São Paulo, 1992. 


\section{AGRADECIMENTOS}

Os autores agradecem ao PRH-PB 221 (Petrobras) e ao NUPRAR (Núcleo de Processamento Primário e Reuso de Aguas Produzidas e Resíduo) pelo apoio financeiro e suporte fornecido para a execução deste trabalho. 